\title{
Brachial plexitis complicating disseminated gonococcal infection
}

\author{
Bassam Maroun, David Rimon and Leon Cohen
}

Department of Internal Medicine B., Lady Davis Carmel Hospital, 34362 Haifa, Israel.

\begin{abstract}
Summary: A patient with brachial plexitis associated with disseminated gonococcal infection is
\end{abstract} presented. This is, to the best of our knowledge, the first case to be reported of this association.

\section{Introduction}

Brachial plexitis (brachial plexus neuropathy) represents a distinct clinical entity with characteristic physical and electromyographic features. The pathogenesis is unknown, although many cases are associated with infectious diseases or surgery. ${ }^{1}$

Gonococcal infection has variable clinical manifestations ranging from otherwise asymptomatic urethral discharge to disseminated infection with cardiac and central nervous system involvement. ${ }^{2}$ Brachial plexitis has not been reported previously in association with disseminated gonococcal infection.

\section{Case report}

A 29 year old man was admitted to the hospital because of arthralgia and minimal urethral discharge following extramarital intercourse. One month earlier he had fever and chills for 2 days, followed by pain and tenderness in the fourth and fifth metacarpophalangeal joints of left hand. One week later, swelling, pain and tenderness appeared in the right knee joint and he was admitted to another hospital where he developed severe aching pain, tenderness and weakness about the left shoulder with limitation of movement in all directions. Within one week, the pain in the left shoulder subsided but weakness became increasingly apparent. The knee joint became free of pain and the patient was discharged with the diagnosis of 'bursitis of left shoulder'.

During the two weeks before the present admission, the patient noticed numbness over the outer side of the left arm. He also gave a history of an intermittent urethral discharge together with pustules over both thighs for a month.

Correspondence: Professor L. Cohen, M.D.

Accepted: 11 August 1988
Examinations revealed normal temperature, an $\Phi$ pustules on thighs and chest. Warmth and tenderness. without associated effusion were present in the lefe wrist and right knee. Mild atrophy and severe paresis of the left deltoid, supraspinatus, infraspinatus and serratus anterior muscles were noticed. A small area of hyposthaesia was present over the outer surface of the arm. A yellowish urethral discharge was observed.

Erythrocyte sedimentation rate, blood count kidney and liver function tests and serum complemen were all normal. Antinuclear antibody, Latex क्षीळ Rose Waaler tests, complement fixation tests Epstein-Barr virus, cytomegalovirus, mycoplasm and toxoplasma were all negative. Enzyme-linkeक immunosorbent assay (ELISA) for humab immunodeficiency virus was non-reactive. Micros copic examination of urethral discharge yielded Neisseria gonorrhoea. X-rays of the chest, shoulders? knees, wrists, hands, feet and cervical spine were normal. Cerebrospinal fluid revealed no abnormat findings and gallium scan was normal.

Electromyography and conduction studies in moto and sensory fibres of the shoulders and arms weré performed. The left side demonstrated fibrillation. potentials and positive waves in the deltoid, supra@ spinatus, infraspinatus and serratus anterior muscles $\$$ Polyphasic waves without interference were observed by active movement. The biceps and first interosse muscles showed no signs of denervation. Nerve cons duction velocities between the wrist and elbow were reduced by $40 \%$ and between elbow and axilla by $20 \%$.

The patient was treated with penicillin -G. Within weeks the numbness subsided completely and weakness of shoulder muscles disappeared graduall by 4 months. A second electromyography and conduc tion studies were performed and showed no abnorm $\frac{\infty}{?}$ ality.

(C) The Fellowship of Postgraduate Medicine, 1989 


\section{Discussion}

Brachial plexitis was first described as a distinct clinical entity in 1943 by Spillane $^{3}$ under the name 'localized neuritis of the shoulder girdle'. Numerous case reports and reviews of large series of patients have since been published..$^{1,4,5-9}$ The aetiology and incidence remain unclear.

This disease is characterized by a sudden onset of severe pain around the shoulder girdle with weakness and wasting of the pericapsular muscles. On subsidence of the pain, motion improves but muscle weakness becomes apparent, followed within several weeks by atrophy of the involved muscle group. Diaphragmatic paralysis has also been reported. ${ }^{10}$ The sensory loss is usually mild. Bilateral involvement was noticed in about $30 \%$ of cases and recurrent attacks affecting the same shoulder may occur. ${ }^{1}$

Brachial plexitis affects mainly adults in the third to the sixth decades and male predominance has been noticed. ${ }^{11}$ Parsonage et al. ${ }^{1}$ found that nearly half the patients have antecedent illnesses. These include infections such as infectious mononucleosis, ${ }^{11,12}$ toxoplasmosis, ${ }^{13}$ mycoplasma pneumonia, ${ }^{14}$ thoracic

\section{References}

1. Parsonage, M.J. \& Turner, J.W.A. Neuralgic amyotrophy, the shoulder-girdle syndrome. Lancet 1948, i: 973-978.

2. James, P.O., Don, L.G. \& Peter, A.R. Disseminated gonococcal infection: a prospective analysis of 49 patients and a review of pathophysiology and immune mechanisms. Medicine 1983, 62: 395-405.

3. Spillane, J.D. Localized neuritis of the shoulder-girdle: A report of 46 cases in the MEF. Lancet 1943, ii: 532-535.

4. Turner, J.W.A. \& Parsonage, M.J. Neuralgic amyotrophy (paralytic brachial neuritis) with special reference to prognosis. Lancet 1957, ii: 209-212.

5. Dillin, L., Hoaglund, F.T. \& Scheck, M. Brachial neuritis. J Bone Joint Surg 1985, 67A: 878-880.

6. Samuel, L.S., Jr. \& Rodney, H.L. Thoracic actinomycosis presenting as a brachial plexus syndrome. Thorax 1985, 40: 74-75.

7. Neundorfer, B., Claus, D. \& Waller, D. Brachial neuritis in salmonellosis. J Neurol 1984, 231: 198-199.

8. Leonard, H.C., Max, R.P., Kerry, H.L., Belinda, Y.L. \& Colleen, S. Acute infection with the human immunodeficiency virus (HIV) associated with acute brachial neuritis and exanthematous rash. Ann Intern Med 1987, 107: 849-851.

9. Allan, S.G., Towla, H.M.A., Smith, C.C., Downie, A.W. \& Clark, J.C. Painful brachial plexopathy: an unusual presentation of polyarteritis nodosa. Postgrad Med J 1982, 58: $311-313$. actinomycosis, ${ }^{6}$ salmonellosis, ${ }^{7}$ malaria, ${ }^{1}$ typhoid fever $^{1}$ and, recently, acute infection with the human immunodeficiency virus. ${ }^{8}$ Also implicated are surgical operations; ${ }^{1}$ polyarteritis nodosa; ${ }^{9}$ systemic lupus erythematosus $;{ }^{15}$ subclavian axillary thrombosis ${ }^{16}$ and following foreign serum injections. ${ }^{11}$ Some authors theorize that a hypersensitivity reaction rather than direct involvement by the underlying disease is responsible for this form of neuropathy, ${ }^{17,18}$ but no immunological mechanisms have been demonstrated.

Despite the severity of the initial pain and paralysis, full recovery is the rule, beginning within a month following the initial symptoms, but complete functional recovery may take up to several years. ${ }^{4}$

The patient under discussion demonstrated classical history, clinical features and neurological findings consistent with the diagnosis of brachial plexitis. He was treated with penicillin and physiotherapy; reexamination 4 months after discharge from hospital revealed normal physical and neurophysiological findings. To our knowledge, no previous report has been published of brachial plexitis associated with disseminated gonococcal infection.

10. Cape, C.A. \& Fincham, R.W. Paralytic brachial neuritis with diaphragmatic paralysis. Contralateral recurrence. Neurology 1965, 15: 191-193.

11. Tsairis, P., Dyck, P.J. \& Mulder, D.W. Natural history of brachial plexus neuropathy. Arch Neurol 1972, 27: $109-117$

12. Schnell, R.B., Dyck, P.J., Bowie, E.J.W., Klass, D.W. \& Taswell, H.F. Infectious mononucleosis: neurologic and EEG findings. Medicine (Baltimore) 1966, 45: 51-63.

13. Tejero, L.J. \& Sauto, C.J.M. Adult toxoplasmosis: considerations on a case with associated bilateral brachial plexitis. Rev Clin Esp 1970, 119: 445-448.

14. Lezer, R.J. \& Kalavsky, S.M. Central nervous system disease associated with Mycoplasma pneumoniae infection: report of five cases and review of the literature. Pediatrics 1973, 52: 658-668.

15. Bloch, S.L., Jarrett, M.P., Swerdlow, M. \& Grcyzel, D.W. Brachial plexus neuropathy as the initial presentation of systemic lupus erythematosus. Neurology 1979, 29: $1633-1634$.

16. Zahu, C.A. \& Wilson, J.J. Association of subclavianaxillary vein thrombosis with brachial neuritis. Can Med Assoc J 1986, 135: 132-133.

17. Wyburn-Mason, $R$. Brachial neuritis occurring in epidemic form. Lancet 1941, ii: 662-663.

18. Turner, J.W.A. Acute brachial radiculitis. $\mathrm{Br}$ Med J 1944, 2: 592. 